\title{
Antibody reactivity against potato apyrase, a protein that shares epitopes with Schistosoma mansoni ATP diphosphohydrolase isoforms, in acute and chronically infected mice, after chemotherapy and reinfection
}

\author{
Priscila de Faria-Pinto ${ }^{1,4}$, Maria Ângela Montesano', Alexandre Arthur Jacinto', \\ Ronaldo Soares Santos ${ }^{1}$, Fábio Humberto S Bordin', Ana Paula Ferreira', Marcus Luiz O Penido², \\ Paulo Marcos Z Coelho ${ }^{3,4}$, Eveline G Vasconcelos ${ }^{1 /+}$
}

'Departamento de Bioquímica, Instituto de Ciências Biológicas, Universidade Federal de Juiz de Fora, Juiz de Fora, MG, Brasil ${ }^{2}$ Departa-
mento de Bioquímica e Imunologia, Instituto de Ciências Biológicas, Universidade Federal de Minas Gerais, Belo Horizonte, MG, Brasil
${ }^{3}$ Instituto de Pesquisas René Rachou-Fiocruz, Belo Horizonte, MG, Brasil ${ }^{4}$ Santa Casa de Belo Horizonte, Belo Horizonte, MG, Brasil

Schistosoma mansoni ATP diphosphohydrolase isoforms and potato apyrase share conserved epitopes. By enzyme-linked immunosorbent assays, elevated levels of IgM, IgG2a and IgGI antibody reactivity against potato apyrase were observed in $\mathrm{S}$. mansoni-infected BALB/c mice during the acute phase of infection, while only IgM and IgG1 antibody reactivity levels maintained elevated during the chronic phase of infection. Antibody reactivity against potato apyrase was monitored over an 11-month period in chronically-infected mice treated with oxamniquine. Eleven months later, the level of seropositive IgM decreased significantly ( 30\%) compared to the level found in untreated, infected mice. The level of seropositive IgG1 decreased significantly four months after treatment (MAT) (61\%) and remained at this level even after 11 months. The IgG2a reactivity against potato apyrase, although unchanged during chronic phase to 11 MAT, appeared elevated again in re-infected mice suggesting a response similar to that found during the acute phase. BALB/c mouse polyclonal anti-potato apyrase IgG reacted with soluble egg antigens probably due to the recognition of parasite ATP diphosphohydrolase. This study, for the first time, showed that the IgG2a antibody from S. mansoni-infected BALB mice cross-reacts with potato apyrase and the level of IgG2a in infected mice differentiates disease phases. The results also suggest that different conserved-epitopes contribute to the immune response in schistosomiasis.

Key words: Schistosoma mansoni - ATP diphosphohydrolase - potato apyrase - antibody - BALB/c mouse - chemotherapy

Two native ATP diphosphohydrolase isoforms, also named apyrases or NTPDases (3.6.1.5) isolated from both Schistosoma mansoni adult worm tegument and egg, have strong cross-immunoreactivity with polyclonal anti-potato apyrase (Faria-Pinto et al. 2004, 2006, Vasconcelos et al. 2009). In addition, total IgG from both $S$. mansoni-infected Swiss Webster mice and schistosomiasis patients showed cross-reactivity with potato apyrase (Faria-Pinto et al. 2004, 2008), which further support the notion that epitopes are shared between the vegetable and $S$. mansoni proteins. In silico analyses revealed domains, theoretically rich in B-cell epitopes, that are highly homologous between potato apyrase and soluble $S$. mansoni ATP diphosphohydrolase isoform but to a lesser extent with a membrane-associated isoform (Faria-Pinto et al. 2008). These proteins share common features, such as the ability to hydrolyse di and triphosphate nucleosides upon bivalent metal ion activation and

Financial support: FAPEMIG, CNPq, CPqRR (to PFP and AAJ), PIBIC, PROBIC/UFJF (to RSS and FHSB)

+ Corresponding author: eveline.vasconcelos@ufjf.edu.br

Received 5 December 2008

Accepted 8 October 2009 are members of the ATP diphosphohydrolase family, which includes isoforms in the same species that are related in amino acid sequence but differ in their solubilisation, subcellular location and/or function (Gendron et al. 2002, Penido et al. 2007, Vasconcelos et al. 2009).

Different levels of IgG isotypes against S. mansoni antigens have been demonstrated before and after chemotherapy in experimental schistosomiasis (Coelho \& Tavares 1991, Ruppel et al. 1991, Ribeiro et al. 2004). In mice, a secondary exposure following chemotherapy showed reduction in granulomatous hypersensitivity to $S$. mansoni eggs compared to a primary infection (Coelho et al. 1996, Farah et al. 2000). Using potato apyrase as an antigen in enzyme-linked immunosorbent assays (ELISA), we investigated the humoral immune response elicited by the conserved epitopes shared between the vegetable and parasite proteins in $S$. mansoni-infected BALB/c mice during acute and chronic phases, after treatment and after re-infection. We showed the immunostimulatory property of the vegetable protein in BALB/c mice and, in addition, cross-reactivity between anti-potato apyrase polyclonal IgG and soluble egg antigens (SEA).

\section{MATERIALS AND METHODS}

Experimental mouse groups - Female BALB/c mice of seven weeks of age used throughout this study were purchased from Centro de Biologia da Reprodução, 
Instituto de Ciências Biológicas, Universidade Federal de Juiz de Fora (UFJF), Minas Gerais (MG), Brazil. Animals were divided into groups and maintained on commercial food pellets and water ad libitum, under a natural dark/ light cycle at RT. They were infected subcutaneously with 25 cercariae of $S$. mansoni that had been maintained in Biomphalaria glabrata snails, infected by miracidia, LE strain, Belo Horizonte, Brazil (Smithers \& Terry 1965). Mouse sera, used as controls, were obtained from sex and age-matched BALB/c mice maintained under the same standard conditions during the time of the experiment. On day 60 (8-9 weeks) and 120 (17 weeks) post-infection, blood samples were obtained from infected $(n=6)$ and uninfected $(\mathrm{n}=6)$ mouse groups and serum samples were stored at $-20^{\circ} \mathrm{C}$. Three additional infected mice were sacrificed under anaesthesia and total worm counts were determined after whole body perfusion with heparinised saline (Pellegrino \& Siqueira 1956). The results show the mean of 12 worms per mouse.

For chemotherapy, on day 127 post-infection, infected and uninfected mice were treated with a single dose of oxamniquine ( $400 \mathrm{mg} / \mathrm{Kg}$ body weight) (Penido et al. 1999) by an oral route. Serum samples were obtained at four and 11 months after treatment (MAT). On the last month, three additional treated, infected mice were sacrificed to control for therapeutic efficacy and no detectable residual worms were observed during the whole body perfusion.

To test the possible reversibility in the levels of antibody after elimination of worms, treated, infected mice $(n=6)$ and treated, uninfected mice $(n=6)$ were infected subcutaneously with a single dose of 100 cercariae one year after the treatment. Fifty days after challenge, sera were obtained. Additional naïve, control animals $(n=6)$ were maintained under standard laboratory care during the entirely of the experiment to monitor the immunological background. Infected mice that did not receive oxamniquine died during experimental period. These studies were approved by the Ethical Committee of the UFJF.

Antibody analysis by ELISA - Potato apyrase was purified from a commercial strain of Solanum tuberosum, as previously described (Kettlun et al. 1992, Faria-Pinto et al. 2004) for use in ELISA. Potato apyrase $(5 \mu \mathrm{g} / \mathrm{well}$ in $0.1 \mathrm{M} \mathrm{NaHCO}_{3}, \mathrm{pH}$ 9.6) was adsorbed on flat-bottom Immunolon II microtiter plates overnight. Following a blocking step $(0.3 \%$ Tween-20, $5 \%$ non-fat dry milk, $0.15 \mathrm{M}$ phosphate buffer solution, $\mathrm{pH}$ 7.2), sera were diluted from 1:100-1:2000 in duplicates in blocking buffer without Tween-20 (Sigma, St. Louis, MO). Antibodies bound to the potato apyrase-plate were detected using peroxidaseconjugated, isotype-specific (Pharmingen, San Diego, $\mathrm{CA})$, anti-mouse IgM (1:5000 dilution), anti-mouse IgG1 (1:1000 dilution) or anti-mouse IgG2a (1:1000 dilution) and o-phenylenediamine dihydrochloride (OPD) as the substrate $\left(\mathrm{OPD} / \mathrm{H}_{2} \mathrm{O}_{2}\right.$ solution). Subsequent colour reaction was read at $492 \mathrm{~nm}$ on a microplate reader (Molecular Devices Corp., Menlo Park, CA). The considered values of $\mathrm{A}_{492}$ were the means of two determinations with a variation of no more than $15 \%$ between them.

Development of polyclonal antiserum against potato apyrase and reactivity of these antibodies against SEA Polyclonal antiserum against potato apyrase was obtained from seven-week old BALB/c mice $(n=4)$ that were inoculated by a peritoneal route with three injections of potato apyrase $(10 \mu \mathrm{g})$; the first injection was emulsified in Freund's complete adjuvant and the other injections were in

TABLE

Antibody reactivity against potato apyrase during experimental schistosomiasis progression

\begin{tabular}{|c|c|c|c|c|}
\hline Stage & Group & $\operatorname{IgM}$ & IgG1 & $\operatorname{IgG} 2 \mathrm{a}$ \\
\hline \multirow{3}{*}{ Acute } & Control & $0.230 \pm 0.055$ & $0.041 \pm 0.009$ & $0.027 \pm 0.009$ \\
\hline & Infected & $0.573 \pm 0.038^{d}$ & $0.307 \pm 0.058^{d}$ & $0.078 \pm 0.036^{d}$ \\
\hline & Control & $0.107 \pm 0.025$ & $0.020 \pm 0.010$ & $0.022 \pm 0.006$ \\
\hline \multirow[t]{2}{*}{ Chronic } & Infected & $0.256 \pm 0.054^{d}$ & $0.227 \pm 0.072^{d}$ & $0.029 \pm 0.012$ \\
\hline & Control & $0.129 \pm 0.030$ & $0.044 \pm 0.022$ & $0.053 \pm 0.021$ \\
\hline \multirow[t]{2}{*}{$4 \mathrm{MAT}^{a}$} & Infected & $0.263 \pm 0.033^{d}$ & $0.204 \pm 0.106^{d}$ & $0.050 \pm 0.018$ \\
\hline & Control & $0.126 \pm 0.037$ & $0.025 \pm 0.010$ & $0.059 \pm 0.037$ \\
\hline \multirow[t]{2}{*}{$11 \mathrm{MAT}^{a}$} & Infected & $0.234 \pm 0.041^{d}$ & $0.097 \pm 0.034^{d}$ & $0.049 \pm 0.026$ \\
\hline & Control & $0.134 \pm 0.038$ & $0.034 \pm 0.011$ & $0.034 \pm 0.007$ \\
\hline \multirow[t]{2}{*}{ Re-infection } & Infected & $0.328 \pm 0.130^{b}$ & $0.169 \pm 0.124^{c}$ & $0.064 \pm 0.021^{d}$ \\
\hline & Control & $0.134 \pm 0.038$ & $0.034 \pm 0.011$ & $0.034 \pm 0.007$ \\
\hline Primo-infection & Infected & $0.359 \pm 0.088^{b}$ & $0.082 \pm 0.043^{b}$ & $0.058 \pm 0.011^{d}$ \\
\hline
\end{tabular}

$a$ : four or 11 months after the treatment (MAT) data in serum diluted 1:1000 are expressed as average \pm SD of optical density; $b$ : $\mathrm{p}<0.05 ; c: \mathrm{p}<0.01 ; d: \mathrm{p}<0.001$, when infected and control were compared. 
Freund's incomplete adjuvant and delivered in 15-day intervals. Pre-immune serum and polyclonal antiserum against potato apyrase were stored at $-20^{\circ} \mathrm{C}$. SEA preparation was obtained as previously described (Colley et al. 1977). The reactivity of total IgG, IgG1 and IgG2 antibodies from preimmune serum (data not shown) or immune serum bound to ELISA plates coated with potato apyrase, ovalbumin or SEA ( $5 \mu \mathrm{g} /$ well) was detected using different serum dilutions (1:50-1:16000) and peroxidase-conjugated isotypespecific secondary antibody and OPD as a substrate using the same procedures as described above.

Statistical analysis - For comparative analysis to account for the day-to-day variation in experimental $S$. mansoni-infection, ELISA units were calculated as the mean of optical density (OD) $(492 \mathrm{~nm})$ values of each duplicate serum samples from each infected mice divided by the mean of the OD of sera from uninfected mice $(n=6)$ plus two standard deviations [OD of each sample/(OD of control + 2SD)]. The mean of the OD of serum samples from these uninfected mice plus two standard deviations correspond to an ELISA unit value of 1 . Therefore, values greater than this cut-off were considered seropositive. GraphPad Prism Software (version 4) was used for statistical analysis. The median and the $95 \%$ confidence interval of ELISA units were calculated and data were analysed using the MannWhitney test to compare two groups or Kruskal-Wallis test to compare three groups. P values of less than 0.05 were considered significant.

\section{RESULTS}

Qualitative differences in antibody isotype profiles against potato apyrase from acute and chronically $S$. mansoni-infected mice after chemotherapy and re-infection - To evaluate the antibody isotype profile, potato apyrase-coated ELISA plates were incubated with diluted sera from BALB/c mice and Table shows the representative data at a serum dilution of 1:1000. In the acute (8-9 weeks post-infection) or chronic (17 week post-infection) phase, the levels of IgM and IgG1 were elevated in serum samples from infected mice, significantly higher than those found in uninfected control mice $(\mathrm{p}<0.001)$, while the level of IgG2a was elevated only in the acute phase serum $(\mathrm{p}<0.001)$ (Table). At four and 11 months after chemotherapy, treated mice maintained significantly higher IgM and IgG1 levels when compared to treated, uninfected mice $(\mathrm{p}<0.001)$, while both groups had similar levels of IgG2a (Table). To test the possible reversibility of antibody levels after elimination of worms, both infected mice treated and cured with oxamniquine (re-infection) and treated, uninfected mice (primo-infection) were challenged with a single dose of 100 cercariae one year after the treatment. Elevated IgM, IgG1 or IgG2a levels against potato apyrase were observed in both re-infected (R) and primoinfected (PI) mice, significantly higher than those found in uninfected mice (Table).

Comparative analysis - The results shown in Table were calculated as arbitrary ELISA units and compared in Fig. 1. IgM against potato apyrase was found during acute and chronic phases, approximately 1.6 -fold higher than the control. The level of potato apyrase-specific IgM was significantly reduced $(\sim 30 \%)$ only at 11 MAT $(\mathrm{p}<0.05)$ when compared to the level in non-treated chronically-infected mice (Fig. 1A). The levels of seropositive IgM were similar in juvenile acutely-infected mice, $R$ and PI mice aged 18 months (Fig. 1A).

The IgG1 seropositivity for potato apyrase was 5-6 fold-higher than the control in acute or chronic phase and reduced significantly $(61 \% ; \mathrm{p}<0.01) 4$ MAT, remaining in the same level (2.2 fold-higher than the control) after 11 MAT (Fig. 1B). The R maintained the similar IgG1 seropositivity (2.9 fold-higher than the control) when compared to the found 11 MAT. The IgG1 seropositivity of PI mice aged 18 months was 1.44 fold-higher than the control, but significantly $(\mathrm{p}<0.001)$ lower than that observed in juvenile acutely-infected mice (Fig. 1B).
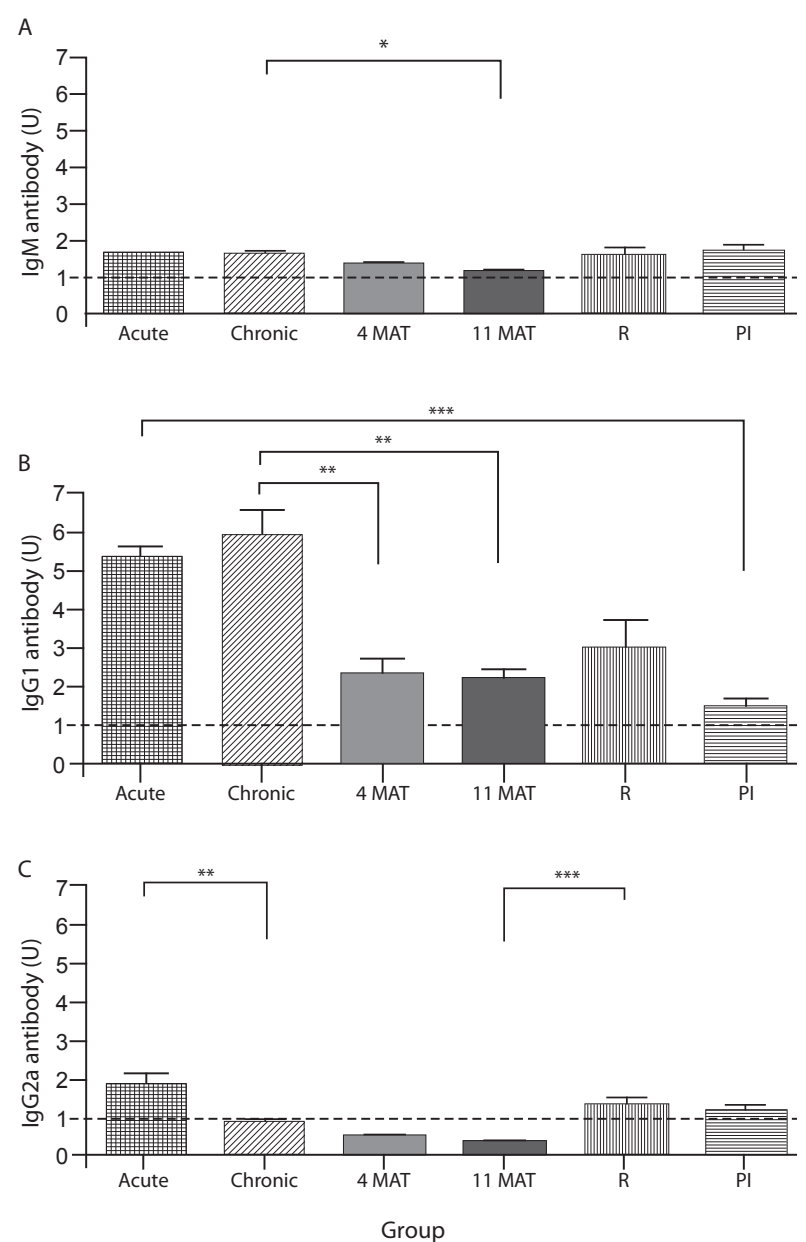

Fig. 1: antibody reactivity against potato apyrase in experimental schistosomiasis. The $\operatorname{IgM}(\mathrm{A}), \operatorname{IgG1}(\mathrm{B})$ or $\operatorname{IgG} 2 \mathrm{a}(\mathrm{C})$ seropositivity for potato apyrase was evaluated in acute (column 1) and chronically (column 2) Schistosoma mansoni-infected BALB/c mice by enzyme-linked immunosorbent assays (ELISA) and compared to the seropositivity at four or 11 months after the treatment (MAT). One year after the chemotherapy, the treated re-infected-mice (R) or treated primo-infected-mice (PI) aged 18 months was infected with 100 cercariae and 50 days after challenge the antibodies were quantified. The data are expressed as average \pm SD of ELISA units (U). *: $\mathrm{p}<0.05 ; * *:<0.01 ; * * ; \mathrm{p}<0.001$. 
The IgG2a seropositivity for potato apyrase was 1.8 higher than the control only in acute phase (Fig. 1C). On the other hand, $\operatorname{IgG} 2$ a seropositivity for potato apyrase could be again observed in R mice and PI mice aged 18 months, at a level that was approximately 1.3 fold-higher than the control and similar to that observed in juvenile acutely-infected mice (Fig. 1C).

Potato apyrase stimulatory property and crossreactivity of polyclonal antibodies against SEA - Inoculation of $\mathrm{BALB} / \mathrm{c}$ mice with potato apyrase induced

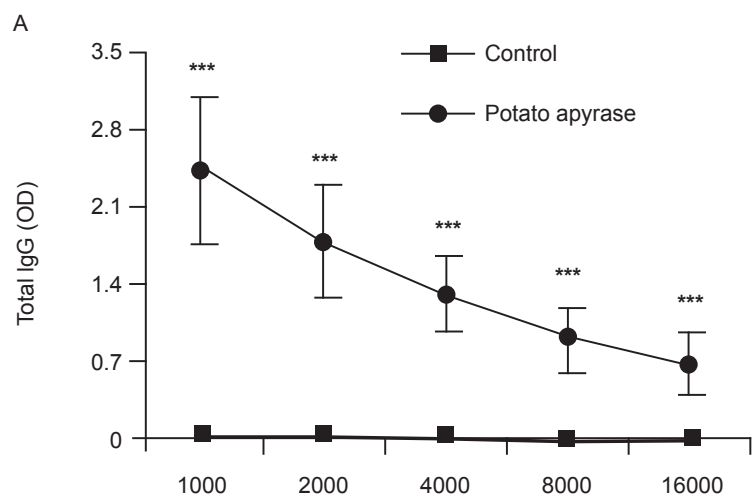

B

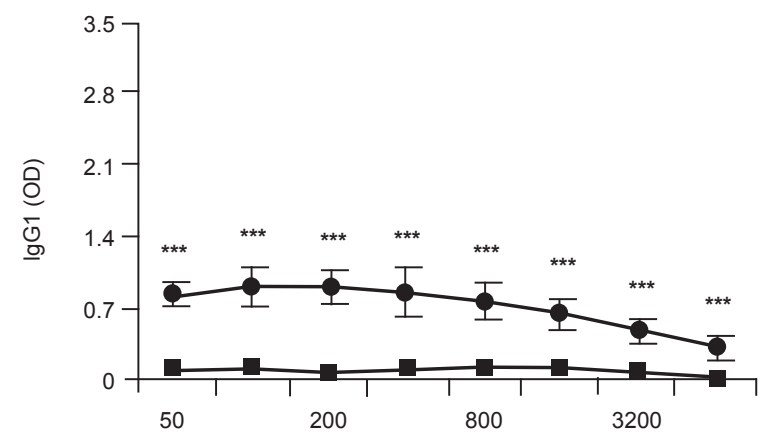

C

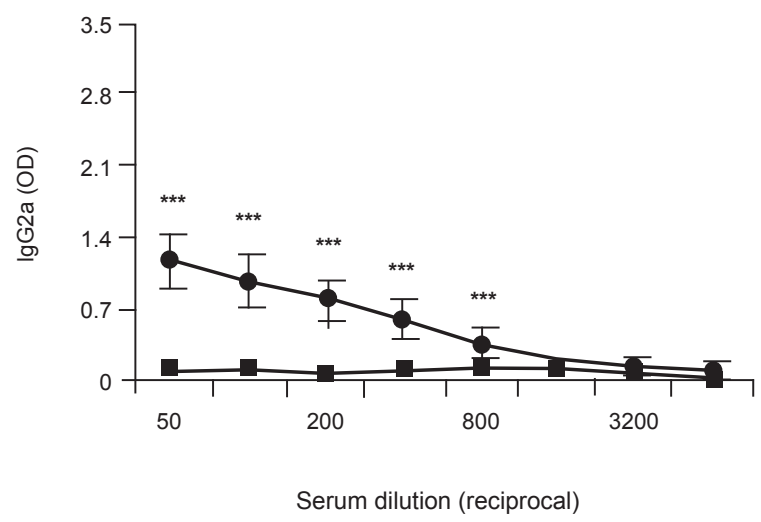

Fig. 2: potato apyrase stimulatory property. Total $\operatorname{IgG}(\mathrm{A})$ and their IgG1 (B) and IgG2a (C) subtypes were quantified in serum samples from $B A L B / c$ mouse $(n=4)$ pre-inoculated with potato apyrase. Potato apyrase or ovalbumin (specificity control) was used as coating antigen in enzyme-linked immunosorbent assays technique. Data are reported as mean $\pm \mathrm{SD}$ of optical density (OD). Asterisks mean $\mathrm{p}<0.001$. significantly high potato apyrase-specific IgG antibody $(>1: 16000)(\mathrm{p}<0.001)$ (Fig. 2A). The levels of IgG1 $(1: 1600)$ and $\operatorname{IgG} 2 \mathrm{a}(1: 800)$ subtypes were also quantified and showed significantly higher levels than the control (Fig. 2B, C). In addition, BALB/c mouse polyclonal anti-potato apyrase $\mathrm{IgG}$ reacted with SEA indicating the possible presence of $S$. mansoni ATP diphosphohydrolase in this antigenic preparation (Fig. 3).

\section{DISCUSSION}

The immunological capacity of the cross-reactivity between potato apyrase and sera from $S$. mansoni-infected $\mathrm{BALB} / \mathrm{c}$ mice to differentiate IgG subsets and disease phases was demonstrated in this paper. A direct correlation between the IgG1 and IgG2a production against domains shared between potato and parasite proteins during the acute phase of infection was observed, while only IgG1 levels remained elevated during the chronic phase. In addition, the level of potato apyrase-specific IgG2a was insignificant between chronic phase and 11 MAT, but appeared again elevated in R BALB/c mice previously treated with oxamniquine, similar to that found in acute phase sera. These results suggest that the humoral immune response against domains shared between potato and parasite proteins may be used as molecular markers to predict the clinical evolution of schistosomiasis and may be particularly useful in the field in assessing changes in the incidence of re-infection during the course of control operations. These properties could be explored in human schistosomiasis.

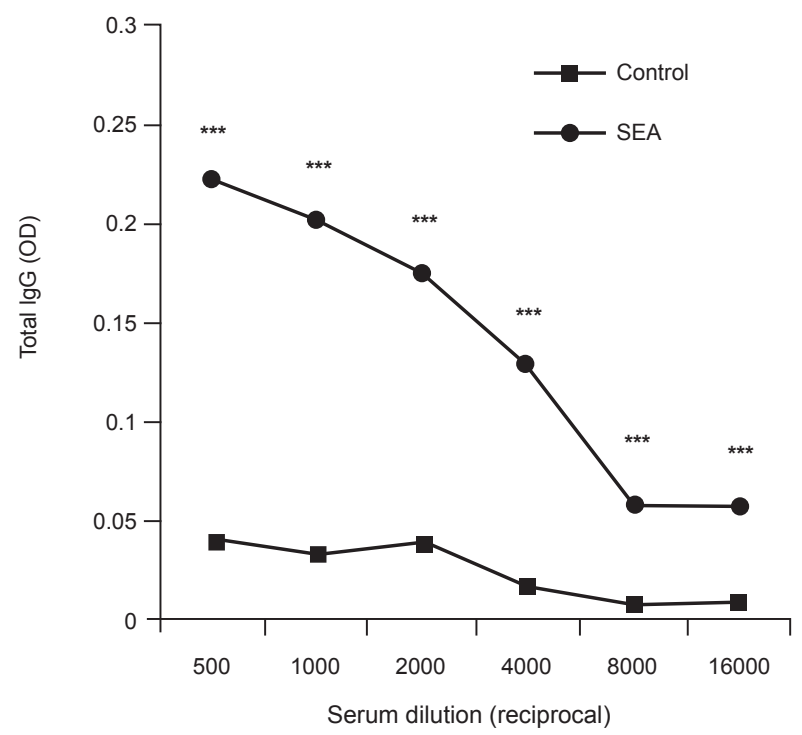

Fig. 3: cross-immunoreactivity between mouse polyclonal IgG antipotato apyrase and soluble egg antigens (SEA). The reactivity of total IgG from BALB/c pre-inoculated with potato apyrase $(n=4)$ was tested against SEA preparation. Ovalbumin was used as control of specificity in enzyme-linked immunosorbent assays technique. The serum samples were diluted from 1:500-1:16000 and tested in duplicate. Data are reported as mean \pm SD of optical density (OD). Asterisks mean $\mathrm{p}<0.001$. 
The IgM and IgG1 reactivity against potato apyrase was reduced 11 months after the treatment. Since the chemotherapeutic treatment eliminated all adult worms, the decrease in antibody levels may be due to a lack of continuous immunological stimulation. It was not possible to maintain a control group of live infected mice in parallel, since only treated mice survived through the final of experiment. Therefore, we cannot eliminate the possibility that the reduction in the antibody level is independent of chemotherapy. However, if this was the case, it is also interesting to observe the longevity of IgG1, a Th2 cytokine-derived isotype, which has been described by other authors to be associated with the downregulation of granulomatous hypersensitivity to $S$. mansoni eggs (Zouain et al. 2000).

Female BALB/c mice aged 18 months infected with 100 cercariae, used as controls for the primary infection, mounted a typical acute immune humoral response against domains shared between potato apyrase and $S$. mansoni ATP diphosphohydrolase isoforms with seropositive IgM, IgG1 and IgG2a. Both IgG1 and IgG2a isotypes showed similar kinetics of induction, lower than levels in sera from juvenile acutely-infected BALB/c mice seven weeks of age that received 25 cercariae. This can be due to either the age of the mice, which could contribute to lower response to the antigenic stimulus or to the cercarial dose, which was higher in this challenge. In the latter case, we anticipated that the amount of primary cercarial exposure and the consequent antigenic load received could be determinants for the type of immune response induced by the shared epitopes.

Therefore, our results suggest that different epitopes of parasite ATP diphosphohydrolase isoforms, also found in potato apyrase, are possibly involved in protection of the host during the early phase of infection and/ or contributing to the schistosomiasis immunomodulation. In fact, $\mathrm{BALB} / \mathrm{c}$ mouse polyclonal anti-potato apyrase IgG react with SEA, possibly recognising $S$. mansoni ATP diphosphohydrolase in this preparation, which further support the existence of conserved domains shared between the vegetable and parasite proteins. In addition, inoculation of the potato apyrase in healthy BALB/c mice has remarkable stimulatory activity, significantly increasing the amount of total $\mathrm{IgG}$, $\mathrm{IgG} 1$ and $\operatorname{IgG} 2$ a subtypes, suggesting that the vegetable protein has distinct epitopes capable of inducing a Th1 or Th2-type immune response. IgG2a, a Th1 cytokinederived isotype, has been described as being protective against schistosomula and adult worms, possibly through antibody-dependent cell cytotoxic mechanisms (Mountford et al. 1994, James et al. 1998, CarvalhoQueiroz et al. 2004). Recently, we demonstrated that rabbit polyclonal antibodies against potato apyrase do not recognise mammalian NTPDases (Faria-Pinto et al. 2006). Therefore, further studies using conserved domains in both parasite and potato apyrase generated by peptide synthesis or cloning and heterologous expression could be explored as molecular markers or used in a vaccine or immunotherapy formulations.

\section{REFERENCES}

Carvalho-Queiroz C, Cook R, Wang CC, Correa-Oliveira R, Bailey NA, Egilmez NK, Mathiowitz E, LoVerde PT 2004. Cross-reactivity of Schistosoma mansoni cytosolic superoxide dismutase, a protective vaccine candidate, with host superoxide dismutase and identification of parasite-specific B epitopes. Infect Immun 72: 2635-2647.

Coelho PM, Tavares CA 1991. ELISA detection of specific circulating antibodies against Schistosoma mansoni in mice after treatment with oxamniquine. Braz J Med Biol Res 24: 485-493.

Coelho PM, Toppa NH, Feldmann JS, Gonçalves R, Mello RT 1996. Schistosoma mansoni: permanence of modulation of the granulomatous inflammatory response in mice cured in the chronic phase. Int J Parasitol 26: 1393-1395.

Colley DG, Cook JA, Freeman Jr GL, Bartholomew RK, Jordan P 1977. Immune responses during human schistosomiasis mansoni. I. In vitro lymphocyte blastogenic responses to heterogeneous antigenic preparations from schistosome eggs, worms and cercariae. Int Arch Allergy Appl Immunol 53: 420-433.

Farah IO, Johansson M, Lövgren-Bengtson K, Hau J 2000. Schistosoma mansoni in mice: the pattern of primary cercarial exposure determines whether a secondary infection post-chemotherapy elicits a $\mathrm{T}$ helper 1- or a $\mathrm{T}$ helper 2-associated immune response. Scand J Immunol 51: 237-243.

Faria-Pinto P, Meirelles MN, Penido ML, Lenzi HL, Mota EM, Coelho PM, Vasconcelos EG 2004. ATP diphosphohydrolase from Schistosoma mansoni egg: characterization and immunocytochemical localization of a new antigen. Parasitology 129: 51-57.

Faria-Pinto P, Meirelles MNL, Lenzi HL, Mota EM, Penido MLO, Coelho PMZ, Vasconcelos EG 2006. Cross-immunoreactivity between anti-potato apyrase antibodies and mammalian ATP diphosphohydrolases: potential use of the vegetal protein in experimental schistosomiasis. Mem Inst Oswaldo Cruz 101 (Suppl. I): $359-363$.

Faria-Pinto P, Rezende-Soares FA, Molica AM, Montesano MA, Marques MJ, Rocha MO, Gomes JA, Enk MJ, Correa-Oliveira R, Coelho PM, Neto SM, Franco OL, Vasconcelos EG 2008. Mapping of the conserved antigenic domains shared between potato apyrase and parasite ATP diphosphohydrolases: potential application in human parasitic diseases. Parasitology 135: 943-953.

Gendron FP, Benrezzak O, Krugh BW, Kong Q, Weisman GA, Beaudoin AR 2002. Purine signaling and potential new therapeutic approach: possible outcomes of NTPDase inhibition. Curr Drug Targets 3: 229-245.

James SL, Cheever AW, Caspar P, Wynn TA 1998. Inducible nitric oxide synthase-deficient mice develop enhanced type 1 cytokineassociated cellular and humoral immune responses after vaccination with attenuated Schistosoma mansoni cercariae but display partially reduced resistance. Infect Immun 66: 3510-3518.

Kettlun AM, Urra R, Leyton M, Valenzuela MA, Mancilla M, TraversoCori A 1992. Purification and characterization of two isoapyrases from Solanum tuberosum var. ultimus. Phytochemistry 31: 3691-3696.

Mountford AP, Fisher A, Wilson RA 1994. The profile of IgG1 and $\mathrm{IgG} 2 \mathrm{a}$ antibody responses in mice exposed to Schistosoma mansoni. Parasite Immunol 16: 521-527.

Pellegrino J, Siqueira AF 1956. A perfusion technic for recovery of Schistosoma mansoni from experimentally infected guinea pigs. Rev Bras Malariol Doencas Trop 8: 589-597.

Penido ML, Coelho PM, Nelson DL 1999. Efficacy of a new schistosomicidal agent 2-[(methylpropyl)amino]-1-octanethiosulfuric 
acid against an oxamniquine resistant Schistosoma mansoni isolate. Mem Inst Oswaldo Cruz 94: 811-813.

Penido ML, Resende DM, Vianello MA, Humberto da Silveira Bordin F, Jacinto AA, Dias WD, Montesano MA, Nelson DL, Coelho PM, Vasconcelos EG 2007. A new series of schistosomicide drugs, the alkylaminoalkanethiosulfuric acids, partially inhibit the activity of Schistosoma mansoni ATP diphosphohydrolase. Eur J Pharmacol 570: 10-17.

Ribeiro F, Mello RT, Tavares CA, Kusel JR, Coelho PM 2004. Synergistic action of praziquantel and host specific immune response against Schistosoma mansoni at different phases of infection. Rev Inst Med Sao Paulo 46: 231-233.

Ruppel A, Xing Y, Dell R, Numrich P, Shi YE 1991. Schistosoma mansoni and S. japoninum: decline of antibodies against diagnos- tic adult worm antigens $(\mathrm{Sm} 31 / 32)$ following praziquantel treatment of mice. Trop Med Parasitol 42: 325-331.

Smithers SR, Terry RJ 1965. The infection of laboratory hosts with cercariae of Schistosoma mansoni and the recovery of the adult worms. Parasitology 55: 695-700.

Vasconcelos EG, Faria-Pinto P, Rezende-Soares FA, Penido ML, Gonçalves-da-Costa SC, Coelho PM 2009. Potato apyrase: a new tool for parasitic disease research. In P Tennant, N Benkeblia (eds), Potato II. Fruit, vegetable and cereal science and biotechnology 3, special issue 1, Global Science Books, UK, p. 80-88.

Zouain CS, Gustavson S, Oliveira SC, Azevedo V, Alves JB, Goes AM 2000. The role of IL-10 and IgG1 in the protection and granulomatous response in Schistosoma mansoni P24-immunized mice. Vaccine 19: 1218-1224. 